\title{
Association between exercise self-efficacy and health-related quality of life among dialysis patients: a cross-sectional study
}

\section{Fan Zhang}

Longhua Hospital Shanghai University of Traditional Chinese Medicine Jing Liao

Longhua Hospital Shanghai University of Traditional Chinese Medicine

\section{Weihong Zhang}

Longhua Hospital Shanghai University of Traditional Chinese Medicine

Hui Wang

Longhua Hospital Shanghai University of Traditional Chinese Medicine

\section{Liuyan Huang}

Longhua Hospital Shanghai University of Traditional Chinese Medicine

\section{Huachun Zhang ( $\square$ lhhlky@163.com )}

Longhua Hospital Shanghai University of Traditional Chinese Medicine https://orcid.org/0000-00027400-0869

\section{Research}

Keywords: Exercise self-efficacy, Physical activity, Quality of life, Dialysis

Posted Date: September 17th, 2021

DOl: https://doi.org/10.21203/rs.3.rs-898466/v1

License: (c) (i) This work is licensed under a Creative Commons Attribution 4.0 International License. Read Full License 


\section{Abstract \\ Background}

Given the importance of exercise self-efficacy in the process of quality of life change, this study aimed to describe the relationship between exercise self-efficacy and health-related quality of life (HRQOL) in dialysis patients.

\section{Methods}

A cross-sectional study was conducted in Shanghai, China. Structured questionnaires applied to the patients collected basic information about gender, age, marital status, education, and income for sociodemographic and body mass index, causes for end-stage renal disease, dialysis modality, and dialysis vintage for the disease-related factors. Physical activity was assessed by a self-administered questionnaire. Exercise self-efficacy was measured through the Exercise Self-Efficacy Scale (ESES). Health-related quality of life was evaluated by the Kidney Disease Quality of Life Instrument-Short Form version 1.3 (KDQOL-SF ${ }^{\mathrm{TM}}$ v1.3). Data were analyzed using a univariate generalized linear model, Spearman correlation, and hierarchical multiple regression.

\section{Results}

A positive association was observed between exercise self-efficacy and HRQOL $(r=0.310, P<0.001)$. Physical activity as predictor variables explained $9.8 \%$ of the variance in overall HRQOL $(P<0.001)$. Exercise self-efficacy explained an additional $7.1 \%$ of the HRQOL variance. In total, $24.6 \%$ of the variation in the HRQOL is explained by the socio-demographic variables, disease-related factors, physical activity, and exercise self-efficacy.

\section{Conclusion}

Overall, only $16.9 \%$ of the change in HRQOL was explained by physical activity and exercise self-efficacy. Future research is still needed to explore further the factors influencing the quality of life in dialysis patients. However, this finding suggests the need to consider the importance of HRQOL and physical activity as well as exercise self-efficacy when developing intervention programs.

\section{Introduction}

Chronic kidney disease is a progressive, debilitating illness defined by declining renal function that gradually progresses to end-stage renal disease (ESRD) [1]. The prevalence of ESRD has increased over the past decade in parallel with an increasing prevalence of diabetes, hypertension, and aging [2, 3]. Dialysis, including hemodialysis and peritoneal dialysis, is an effective renal replacement therapy 
modality for patients with ESRD. Over the next five years, the number of dialysis patients is estimated to be nearly 900,000 cases in China [4], and it has emerged as one of the most critical public health problems worldwide [5]. Due to the complexity of the disease process and its management, dialysis treatment imposes significant security and financial burden on patients and their families, seriously affecting health-related quality of life (HRQOL) [6].

$\mathrm{HRQOL}$ is seen as a primary patient-centered outcome and is increasingly used as an assessment metric for medical interventions [7]. HRQOL can predict disease-related factors and assess prognosis, thus guiding the treatment of specific populations. Poor HRQOL was a common problem in dialysis patients and contributed to low survival rates [8, 9] and high emotional stress [8]. With this in mind, HRQOL is increasingly recognized as a key prognostic measure to evaluate the effectiveness of kidney disease treatment [9].

Exercise self-efficacy, the confidence a person has in developing and meeting exercise goals, is vital to exercise motivation [10]. Results of a previous study showed the level of exercise self-efficacy is low in patients with chronic diseases [11], which was associated with poor HRQOL in some populations, e.g., chronic heart failure [12], total knee arthroplasty recipients [13]. The literature indicated that exercise selfefficacy is a predictor of good HRQOL [14], and low exercise self-efficacy often leads to physical inactivity, causing poor prognosis [15-17]. In addition, good self-efficacy appears to be critical for improving HRQOL and health status, primarily when targeted secondary prevention strategies are working to achieve desired rates [18].

To address and help bridge the gap between exercise self-efficacy and HRQOL, we conducted a crosssectional study to explore the association between exercise self-efficacy and HRQOL in ESRD patients receiving dialysis treatment.

\section{Methods}

\section{Study design and population}

The study was conducted between October 2020 to June 2021. Using a snowball sampling method, samples were obtained from the nephrology department of a hospital in Shanghai. The sample size should be $5-10$ times the number of scale entries. Considering a $10 \%$ inefficiency of the questionnaire, it is expected that a minimum of 198 participants will be needed. The inclusion criteria were as follows: diagnosed with ESRD and already undergoing regular dialysis treatment; age older than 18 years; able to perform the activities of daily living independently; able to understand and speak Chinese; consent to participate in the study. The exclusion criteria were cognitive impairment or mental disorders; refusal to participate. Patients who used a cane daily or had difficulty walking without a walking aid device were also excluded.

\section{Assessments}


The assessment tools for collecting data included: (1) basic information questionnaire; (2) physical activity questionnaire; (3) Exercise Self-efficacy Scale; (4) Kidney Disease Quality of Life Scale.

\section{Instruments}

\section{Basic information questionnaire}

The socio-demographic questionnaire consisted of gender, age, marital status, education, and income. The disease-related factors included body mass index, causes for end-stage renal disease, dialysis modality, and dialysis vintage.

\section{Physical activity}

Physical activity level was evaluated by reporting how often an individual exercised $(\leq 1,2-3, \geq 4$ sessions per week), and the mean duration of each exercise session ( $<30,30-45,45-60,>60$ minutes per session).

\section{Exercise Self-Efficacy Scale}

The Exercise Self-Efficacy Scale was used to measure exercise self-efficacy, developed by Bandura [19]. For each item, individuals indicate their confidence to execute the behavior on a 100-point percentage scale comprised of 10-point increments, ranging from $0 \%$ (not at all confident) to $100 \%$ (highly confident). Total strength for each measure of self-efficacy is then calculated by summing the confidence ratings and dividing by the total number of items in the scale, resulting in a maximum possible efficacy score of 100. The Chinese version of the scale has good validity and reliability with a Cronbach's alpha of 0.966 [20].

\section{Kidney Disease Quality of Life Scale}

Kidney Disease Quality of Life Scale (KDQOL-SF ${ }^{T M}$ v1.3), a 36-item disease-specific questionnaire, was employed to evaluate the patients' quality of life. The scale consists of five dimensions: Physical Component Summary (PCS), Mental Component Summary (MCS), Burden of Kidney Disease, Symptom/Problem, and Effects of Kidney Disease. The score was ranged from 0 to 100, with the higher the of each dimension indicating a better quality of life. The Chinese version of the KDQOL-36 ${ }^{\mathrm{TM}}$ has demonstrated acceptable levels of internal consistency (Cronbach's $a=0.69-0.78$ ) and test-retest reliability (ICC=0.70-0.86) [21].

\section{Statistical analysis}

Categorical variables were presented as frequency (percentage) and Continuous variables as mean \pm standard deviations because the overall HRQOL score was normally distributed.

A univariate generalized linear model was used to analyze the relationship between each independent variable and HRQOL. Consider the distribution of exercise self-efficacy scores was skewed, the spearman correlation was used to assess the relationship between exercise self-efficacy and HRQOL. 
In the hierarchical regression analysis, the model was entered in 4 blocks. Block 1 consisted of gender, age, marital status, educational, and income which were operationally defined as socio-demographic and were entered first. Block 2 was disease-related factors, including body mass index, causes of end-stage renal disease, dialysis modality, and dialysis vintage. Block 3 included physical activity, and the exercise self-efficacy was added to block 4 . After the entry of each block, the adjusted $\mathrm{R}^{2}$ change is observed to determine the proportion of variance described by HRQOL. The significant level was set at 0.05 . Statistical analysis was performed using SPSS software (version 21.0).

\section{Results}

A total of 203 participants were finally included in this survey. Table 1 demonstrates the sociodemographic of the participants. The mean age of participants was $58.57 \pm 12.07$ years and among the 203 patients. More than half of the participants $(n=58.13 \%)$ had a lower physical activity $(<1500$ $\mathrm{min} /$ week). 
Table 1

Characteristics of included patients according to socio-demographic $(n=203)$

\begin{tabular}{|c|c|c|c|}
\hline Variables & $\mathrm{n}(\%)$ & $\beta(95 \% \mathrm{Cl})$ & $P$ value \\
\hline \multicolumn{4}{|l|}{ Gender } \\
\hline Male & $114(56.16 \%)$ & - & \\
\hline Female & $89(43.84 \%)$ & $-1.402(-4.528,1.729)$ & 0.380 \\
\hline \multicolumn{4}{|l|}{ Age (years) } \\
\hline$<55$ & $66(32.51 \%)$ & - & \\
\hline$\geq 55$ & $137(67.49 \%)$ & $0.023(-0.108,0.153)$ & 0.731 \\
\hline \multicolumn{4}{|l|}{ Marital status } \\
\hline Non-married & $21(10.34 \%)$ & - & \\
\hline Married & $162(79.80 \%)$ & $4.713(-0.378,9.805)$ & 0.070 \\
\hline Widowed & $20(9.85 \%)$ & $5.395(-1.464,12.255)$ & 0.123 \\
\hline \multicolumn{4}{|l|}{ Educational } \\
\hline Primary school or below & $18(8.87 \%)$ & - & \\
\hline Junior high school & $86(42.36 \%)$ & $-1.314(-7.041,4.412)$ & 0.362 \\
\hline Senior high school & $65(32.02 \%)$ & $-1.520(-7.404,4.365)$ & 0.613 \\
\hline Undergraduate or above & $34(16.75 \%)$ & $-2.996(-9.436,3.444)$ & 0.653 \\
\hline \multicolumn{4}{|l|}{ Income } \\
\hline Poor & $50(24.63 \%)$ & - & \\
\hline Moderate & $66(32.51 \%)$ & $3.900(-0.200,7.999)$ & 0.062 \\
\hline Good & $56(27.59 \%)$ & $0.236(-4.019,4.490)$ & 0.913 \\
\hline Very good & $31(15.27 \%)$ & $0.034(-4.965,5.033)$ & 0.989 \\
\hline \multicolumn{4}{|l|}{ Causes } \\
\hline Glomerulonephritis & 77 (37.93\%) & - & \\
\hline Diabetic nephropathy & $47(23.15 \%)$ & $0.032(-4.057,4.121)$ & 0.988 \\
\hline Hypertensive nephropathy & $35(17.24 \%)$ & $0.821(-3.683,5.325)$ & 0.721 \\
\hline IgA nephropathy & $22(10.84 \%)$ & $1.945(-3.396,7.285)$ & 0.475 \\
\hline Other & $22(10.84 \%)$ & $1.855(-3.486,7.196)$ & 0.496 \\
\hline
\end{tabular}




\begin{tabular}{|llll|}
\hline Variables & $\mathbf{n}(\%)$ & $\boldsymbol{\beta}(95 \% \mathrm{Cl})$ & $\boldsymbol{P}$ value \\
\hline Underweight & $14(6.90 \%)$ & - & \\
\hline Normal & $115(56.65 \%)$ & $2.711(-3.525,8.946)$ & 0.394 \\
\hline Overweight & $62(30.54 \%)$ & $2.034(-4.484,8.552)$ & 0.541 \\
\hline Obesity & $12(5.91 \%)$ & $-1.617(-10.283,7.048)$ & 0.715 \\
\hline Dialysis modality & & & \\
\hline Peritoneal dialysis & $116(58.13 \%)$ & - & 0.005 \\
\hline Hemodialysis & $87(42.86 \%)$ & $4.443(1.363,7.523)$ & \\
\hline Dialysis vintage (months) & & & 0.041 \\
\hline$<36$ & $78(38.42 \%)$ & - & 0.430 \\
\hline $36-60$ & $69(33.99 \%)$ & $-3.780(-7.403,-0.158)$ & 0.016 \\
\hline$>60$ & $56(27.59 \%)$ & $-1.546(-5.385,2.293)$ & \\
\hline Physical activity (min/week) & & & \\
\hline$<1500$ & $118(58.13 \%)$ & - & \\
\hline$\geq 1500$ & $85(41.87 \%)$ & $3.842(0.706,6.978)$ & \\
\hline
\end{tabular}

\section{Health-related Quality Of Life}

The mean score of dialysis patients' quality of life was $49.51 \pm 11.33$. The comparison of the mean scores for each dimension of the scale in the study population showed that "Burden of Kidney Disease" $(38.08 \pm 26.73)$ had the lowest mean score and "Symptom/Problem" (77.85 \pm 14.28$)$ had the highest mean score among all the studied dimensions, see Fig. 1.

Figure 2 shows the Spearman correlation between exercise self-efficacy and HRQOL, and a positive association was observed $(r=0.310, P<0.001)$.

\section{Hierarchical Regression Models}

Table 2 shows the results of the hierarchical regression models. In model 1, socio-demographic could explain $2.3 \%$ of the variation in $\mathrm{KDQOL}$, with an $\mathrm{R}^{2}$ value was 0.026 . For model 2 , disease-related factors have an explanatory strength of $5.3 \%$ for KDQOL, and the $\mathrm{R}^{2}$ increased from 0.023 to 0.076 . Model 3 showed a significant change in F-value $(P<0.05)$ with the addition of physical activity to model 2 , implying that physical activity has an explanatory significance to the model. Moreover, the R2 value increased from 0.076 to 0.174 , implying that physical activity can generate an explanatory strength of 
$9.8 \%$ for KDQOL. Specifically, the regression coefficient value for physical activity is $8.242(t=4.772, P<$ 0.001 ), implying that physical activity can significantly positively correlate with KDQOL. In model 4 , exercise self-efficacy was added, which explained an additional $7.1 \%$ variation, with the $\mathrm{R}^{2}$ value increasing to 0.246 . The regression coefficient value of exercise self-efficacy was $0.472(t=4.234, P<$ 0.001), implying that exercise self-efficacy would have a significant positive relationship with KDQOL. 
Table 2

Hierarchical linear regression for prediction $\mathrm{HRQOL}$

\begin{tabular}{|c|c|c|c|c|}
\hline & Model 1 & Model 2 & Model 3 & Model 4 \\
\hline \multirow[t]{2}{*}{ Sex } & -1.641 & -1.418 & -1.094 & -0.939 \\
\hline & $(-0.995)$ & $(-0.859)$ & $(-0.699)$ & $(-0.626)$ \\
\hline \multirow[t]{2}{*}{ Age } & 1.276 & 0.418 & 2.526 & 2.834 \\
\hline & $(0.682)$ & $(0.221)$ & $(1.366)$ & $(1.599)$ \\
\hline \multirow[t]{2}{*}{ Income } & -0.413 & 1.140 & 1.399 & 1.209 \\
\hline & $(-0.490)$ & $(1.193)$ & $(1.542)$ & $(1.388)$ \\
\hline \multirow[t]{2}{*}{ Education } & -0.589 & -1.736 & -1.877 & -1.277 \\
\hline & $(-0.574)$ & $(-1.609)$ & $(-1.834)$ & $(-1.289)$ \\
\hline \multirow[t]{2}{*}{ Marry } & 2.205 & 2.189 & $3.955^{\star}$ & 3.074 \\
\hline & $(1.163)$ & $(1.165)$ & $(2.174)$ & $(1.751)$ \\
\hline \multirow[t]{2}{*}{ Dialysis } & & $5.515^{\star \star}$ & $7.614 * \star$ & $7.912^{\star \star}$ \\
\hline & & $(2.980)$ & $(4.209)$ & $(4.561)$ \\
\hline \multirow[t]{2}{*}{ Dialysis vintage } & & -0.699 & -1.159 & -1.423 \\
\hline & & $(-0.708)$ & $(-1.232)$ & $(-1.575)$ \\
\hline \multirow[t]{2}{*}{ Morbidity } & & 0.479 & 0.751 & 0.555 \\
\hline & & $(0.819)$ & $(1.348)$ & $(1.035)$ \\
\hline \multirow[t]{2}{*}{ Body mass index } & & -1.005 & -1.742 & -1.766 \\
\hline & & $(-0.860)$ & $(-1.557)$ & $(-1.648)$ \\
\hline \multirow[t]{2}{*}{ Physical activity } & & & $8.242^{\star \star}$ & $6.703^{\star \star}$ \\
\hline & & & $(4.772)$ & (3.957) \\
\hline \multirow[t]{2}{*}{ SESE } & & & & $0.472^{\star \star}$ \\
\hline & & & & $(4.254)$ \\
\hline $\mathrm{R}^{2}$ & 0.023 & 0.076 & 0.174 & 0.246 \\
\hline Adjusted $\mathrm{R}^{2}$ & -0.002 & 0.033 & 0.131 & 0.202 \\
\hline
\end{tabular}

* $P<0.05$ ** $P<0.001$

Values in the parenthesis are $t$ values. 


\begin{tabular}{|lllll|}
\hline & Model 1 & Model 2 & Model 3 & Model 4 \\
\hline$F$ & $F(5,197)=0.924$ & $F(9,193)=1.773$ & $F(10,192)=4.053$ & $F(11,191)=5.657$ \\
\hline$P$ value for $F$ & $P=0.466$ & $P=0.076$ & $P<0.001$ & $P<0.001$ \\
\hline $\mathrm{R}^{2}$ & 0.023 & 0.053 & 0.098 & 0.071 \\
\hline$F$ & $F(5,197)=0.924$ & $F(4,193)=2.791$ & $F(1,192)=22.773$ & $F(1,191)=18.096$ \\
\hline$* P<0.05 * * P<0.001$ & & & \\
\hline \multicolumn{2}{|l}{ Values in the parenthesis are $t$ values. } & & & \\
\hline
\end{tabular}

\section{Discussion}

As dialysis technology improves and kidney disease patients live longer, healthcare providers are placing greater emphasis on patients' HRQOL.

A recent meta-analysis involving 147 studies reported a pooling mean HRQOL score for patients undergoing dialysis was 64.25 (95\% $\mathrm{Cl} 55.67$ to 72.82$)$ [22]. In the present study, the overall mean score of HRQOL was modestly lower than the results mentioned above. The reason may be that the average age of the patients enrolled in this study was older (58.57 \pm 12.07$)$. As described in the study by Ishiwatari et al., dialysis patients' quality of life decreased over time, especially among those older adults [23].

From the viewpoint of all dimensions, except MCS, all are lower than a large sample of the USA data [24], where only Symptom/Problem is not statistically significant, see Fig. 1. This may be related to the faster development of dialysis technology in the United States [25]. In addition, the results of low scores in each dimension may be related to the kidney disease itself, as well as existing comorbidities and related disease complications. The lowest burden of kidney disease score was similar to the results of the Peritoneal and Dialysis Outcomes and Practice Patterns Studies [26], indicating that disease burden is an important cause of lower quality of life for dialysis patients. As concluded by Abeywickrama et al., the symptoms burden score independently influenced all HRQOL (PCS: $\beta=-0.417$; MCS: $\beta=-0.464$ ) [27].

In the univariate analysis, dialysis type, dialysis vintage, and physical activity represented predictors for HRQOL in dialysis patients. Unlike previous studies [28], the results of this study showed that the HRQOL scores of hemodialysis patients were 4.443 (OR: 1.363, 7.523; $P=0.005)$ higher than those of peritoneal dialysis patients, but similar to the results of Gonçalves et al. [29] and de Abreu et al. [30] This happened because the limited sample size and the different inclusion criteria.

Regarding dialysis vintage, we found that patients with longer dialysis vintage had lower HRQOL scores than those with shorter ones. Early studies have shown that patients with kidney disease quality of life tend to decrease year by year after dialysis initiation [31,32]. This is because the number of medications and co-morbidities increases with dialysis vintage, further eroding quality of life [33]. Therefore, Boini et 
al. emphasized that HRQOL at dialysis initiation is significantly influenced by the quality of predialysis nephrology care and that emphasis should be placed on disease management [34].

The relationship of interest between physical activity and the prognosis of dialysis patients has been widely recognized [35]. As in previous studies, the results of this study showed that patients who participated in higher levels of physical activity had higher HRQOL scores compared to those who were less physically active than recommended. Previous studies have shown that physical activity increases the HRQOL of dialysis patients by improving cardiovascular health, inflammatory status, physical fitness, and reducing disease-related symptoms [36-38].

Moreover, in the current study, a significant positive interrelation was found between exercise self-efficacy and HRQOL. This positive relationship corroborates the social cognitive model proposed by McAuley et al. that exercise self-efficacy has a positive effect on PCS and MCS [39]. Self-efficacy has been reported to be the most dominant factor in the uptake and maintenance of exercise in populations with chronic conditions $[40,41]$. Furthermore, self-efficacy is an essential determinant of health behavior, associated with a positive quality of life among patients living with chronic illnesses $[42,43]$.

In the stratified regression analysis, our study presented that physical activity remained statistically significant positive correlation with HRQOL. Also, physical activity as a predictor variable can explain an additional $9.8 \%$ of the variation in HRQOL. Most of the studies found a positive relationship between physical activity and HRQOL as well as a negative relationship between sedentary behavior and HRQOL among dialysis patients [44-46]. The present study further confirmed this positive finding. Moreover, we found that exercise self-efficacy was an important predictor of HRQOL in dialysis patients. Exercise selfefficacy is a strong determinant of behavior in physical activity and other health domains and has been shown to correlate with HRQOL in other populations $[17,18,47]$. The results of this study reinforce existing evidence on the importance of self-efficacy as a determinant of HRQOL in patients with chronic disease. Therefore, interventions aiming at increasing the HRQOL of dialysis patients should consider physical activity and exercise self-efficacy in these populations.

Our study has several limitations. Firstly, conducted in single-center, the results limit generalizability. Meanwhile, this study focused only on a sample of the dialysis population and has limited universality to non-dialysis CKD patients. Secondly, self-administered questionnaires were used to assess physical activity; an inaccurate estimation and recall bias was unavoidable. Thirdly, this study used a crosssectional design and could not infer a causal relationship between exercise self-efficacy and HRQOL. Finally, we were unable to control the intensity of physical activity, and since we did not collect relevant data, this may have confounded the relationship between key variables.

\section{Conclusions}

The present study revealed that overall HRQOL in dialysis patients was low, while the burden of kidney disease dimension was the most impacted. Dialysis modality, dialysis vintage, physical activity, and exercise self-efficacy were significantly associated with poor overall HRQOL in our study population. In 
total, only $16.9 \%$ of the variation of HRQOL was explained by the physical activity and exercise selfefficacy, and future studies still need to expand the sample size to explore potential predictors further. Nonetheless, this finding recommends the importance of considering HRQOL and physical activity and exercise self-efficacy when developing intervention programs.

\section{Abbreviations}

ESES: Exercise Self-Efficacy Scale; KDQOL-SF ${ }^{\mathrm{TM}} \mathrm{V} 1.3$ : Kidney Disease Quality of Life Instrument-Short Form version 1.3; ESRD: end-stage renal disease; HRQOL: health-related quality of life; BMI: body mass index.

\section{Declarations}

\section{Ethics approval and consent to participate}

The study was approved by the Ethics Committee in Longhua Hospital Shanghai University of Traditional Chinese Medicine. All patients participated voluntarily in the survey and signed a free, informed consent form.

\section{Consent for publication}

Not applicable.

\section{Availability of data and materials}

Study data are available on reasonable request from the first author (Fan Zhang)

\section{Competing interests}

The authors declare that they have no competing interests in this section.

\section{Funding}

This study was supported by Longhua Hospital Shanghai University of Traditional Chinese Medicine (Grant number: Y21026).

\section{Authors' contributions}

Fan Zhang and Jing Liao worked in the conception and design of the study. Weihong Zhang, Jing Liao, and Liuyan Huang worked in data collection. Fan Zhang worked on data analysis and wrote the first draft. Liuyan Huang and Huachun Zhang revised the draft, and all authors have approved the final version for publication.

\section{Acknowledgments}


We thank all patients for participating in the present study.

\section{References}

1. Webster AC, Nagler EV, Morton RL, Masson P. Chronic Kidney Disease. Lancet. 2017;389(10075):1238-52.

2. Cheng HT, Xu X, Lim PS, Hung KY. Worldwide Epidemiology of Diabetes-Related End-Stage Renal Disease, 2000-2015. Diabetes Care. 2021;44(1):89-97.

3. Rhee CM, Kovesdy CP. Epidemiology: Spotlight on CKD deaths-increasing mortality worldwide. Nat Rev Nephrol. 2015;11(4):199-200.

4. Yang C, Yang Z, Wang J, Wang HY, Su Z, Chen R, Sun X, Gao B, Wang F, Zhang L, et al. Estimation of Prevalence of Kidney Disease Treated With Dialysis in China: A Study of Insurance Claims Data. Am J Kidney Dis. 2021;77(6):889-97.e881.

5. Wang F, Yang C, Long J, Zhao X, Tang W, Zhang D, Bai K, Su Z, Gao B, Chu H, et al. Executive summary for the 2015 Annual Data Report of the China Kidney Disease Network (CK-NET). Kidney Int. 2019;95(3):501-5.

6. Coresh J. Update on the Burden of CKD. J Am Soc Nephrol. 2017;28(4):1020-2.

7. Segura-Orti E, Koufaki P, Kouidi E. Bridging the gap from research to practice for enhanced healthrelated quality of life in people with chronic kidney disease. Clin Kidney J. 2021;14(Suppl 2):ii34-42.

8. Yapa HE, Purtell L, Chambers S, Bonner A. Alterations in symptoms and health-related quality of life as kidney function deteriorates: A cross-sectional study. J Clin Nurs. 2021;30(11-12):1787-96.

9. Lightfoot CJ, Howell M, Smith AC. How to assess quality of life in persons with chronic kidney disease. Curr Opin Nephrol Hypertens 2021.

10. O'Neil-Pirozzi TM. Cognitive Exercise Self-Efficacy of Community-Dwelling Older Adults: Measurement and Associations with Other Self-Reported Cognitive Exercise Factors. Brain Sci 2021, 11(6).

11. Almutary $\mathrm{H}$, Tayyib N. Factors associated with exercise self-efficacy among people with chronic diseases. Appl Nurs Res. 2020;54:151275.

12. Lee H, Boo S, Yu J, Suh SR, Chun KJ, Kim JH. Physical Functioning, Physical Activity, Exercise SelfEfficacy, and Quality of Life Among Individuals With Chronic Heart Failure in Korea: A CrossSectional Descriptive Study. J Nurs Res. 2017;25(2):131-9.

13. Tobinaga T, Obayashi S, Miyazaki C, Yazawa M, Saito T, Hashimoto K, Ogawa M, Tochigi Y, Oka K, Ozeki S. The impact of self-efficacy for physical activity on health-related quality of life in total knee arthroplasty recipients. J Back Musculoskelet Rehabil 2021.

14. Ogwumike OO, Omoregie AA, Dada OO, Badaru UM. Quality of life of stroke survivors: A crosssectional study of association with functional independence, self-reported fatigue and exercise selfefficacy. Chronic IIIn 2021:17423953211023960. 
15. Farris SG, Davis ML, Rosenfield D, Kauffman BY, Baird SO, Powers MB, Otto MW, Marcus BH, Church TS, Smits JA, et al. Exercise Self-Efficacy Moderates the Relation between Anxiety Sensitivity and Body Mass Index and Exercise Tolerance in Treatment-Seeking Smokers. Ment Health Phys Act. 2016;10:25-32.

16. Kooijmans H, Post M, Motazedi E, Spijkerman D, Bongers-Janssen H, Stam H, Bussman H. Exercise self-efficacy is weakly related to engagement in physical activity in persons with long-standing spinal cord injury. Disabil Rehabil. 2020;42(20):2903-9.

17. Selzler AM, Rodgers WM, Berry TR, Stickland MK. The importance of exercise self-efficacy for clinical outcomes in pulmonary rehabilitation. Rehabil Psychol. 2016;61(4):380-8.

18. Stevens A, Stanton R, Rebar AL. Helping People With Parkinson Disease Build Exercise Self-Efficacy. Phys Ther. 2020;100(2):205-8.

19. Tung WC, Gillett PA, Pattillo RE. Applying the Transtheoretical Model to physical activity in family caregivers in Taiwan. Public Health Nurs. 2005;22(4):299-310.

20. Zhang Y, Xue G. [Reliability and validity test of Exercise Self-Efficacy Scale in maintenance hemodialysis patients]. Chin Nurs Res. 2019;33(18):3133-6.

21. Tao X, Chow SK, Wong FK. Determining the validity and reliability of the Chinese version of the Kidney Disease Quality of Life Questionnaire (KDQOL-36 ${ }^{\mathrm{TM}}$ ). BMC Nephrol. 2014;15:115.

22. Raoofi S, Pashazadeh Kan F, Rafiei S, Hoseinipalangi Z, Rezaei S, Ahmadi S, Masoumi M, Noorani Mejareh Z, Roohravan Benis M, Sharifı A, et al: Hemodialysis and peritoneal dialysis-health-related quality of life: systematic review plus meta-analysis. BMJ Support Palliat Care 2021.

23. Ishiwatari A, Yamamoto S, Fukuma S, Hasegawa T, Wakai S, Nangaku M. Changes in Quality of Life in Older Hemodialysis Patients: A Cohort Study on Dialysis Outcomes and Practice Patterns. Am J Nephrol. 2020;51(8):650-8.

24. Cohen DE, Lee A, Sibbel S, Benner D, Brunelli SM, Tentori F. Use of the KDQOL-36 ${ }^{\text {TM }}$ for assessment of health-related quality of life among dialysis patients in the United States. BMC Nephrol. 2019;20(1):112.

25. Kurella Tamura M, Thomas IC, Montez-Rath ME, Kapphahn K, Desai M, Gale RC, Asch SM. Dialysis Initiation and Mortality Among Older Veterans With Kidney Failure Treated in Medicare vs the Department of Veterans Affairs. JAMA Intern Med. 2018;178(5):657-64.

26. Brown EA, Zhao J, McCullough K, Fuller DS, Figueiredo AE, Bieber B, Finkelstein FO, Shen J, Kanjanabuch T, Kawanishi H, et al: Burden of Kidney Disease, Health-Related Quality of Life, and Employment Among Patients Receiving Peritoneal Dialysis and In-Center Hemodialysis: Findings From the DOPPS Program. Am J Kidney Dis 2021.

27. Abeywickrama HM, Wimalasiri S, Koyama Y, Uchiyama M, Shimizu U, Kakihara N, Chandrajith R, Nanayakkara N. Quality of Life and Symptom Burden among Chronic Kidney Disease of Uncertain Etiology (CKDu) Patients in Girandurukotte, Sri Lanka. Int J Environ Res Public Health 2020, 17(11).

28. Chuasuwan A, Pooripussarakul S, Thakkinstian A, Ingsathit A, Pattanaprateep O. Comparisons of quality of life between patients underwent peritoneal dialysis and hemodialysis: a systematic review 
and meta-analysis. Health Qual Life Outcomes. 2020;18(1):191.

29. Gonçalves FA, Dalosso IF, Borba JM, Bucaneve J, Valerio NM, Okamoto CT, Bucharles SG. Quality of life in chronic renal patients on hemodialysis or peritoneal dialysis: a comparative study in a referral service of Curitiba - PR. J Bras Nefrol. 2015;37(4):467-74.

30. de Abreu MM, Walker DR, Sesso RC, Ferraz MB. Health-related quality of life of patients recieving hemodialysis and peritoneal dialysis in São Paulo, Brazil: a longitudinal study. Value Health. 2011;14(5 Suppl 1):119-21.

31. Jung HY, Jeon Y, Park Y, Kim YS, Kang SW, Yang CW, Kim NH, Choi JY, Cho JH, Park SH, et al. Better Quality of Life of Peritoneal Dialysis compared to Hemodialysis over a Two-year Period after Dialysis Initiation. Sci Rep. 2019;9(1):10266.

32. Eneanya ND, Maddux DW, Reviriego-Mendoza MM, Larkin JW, Usvyat LA, van der Sande FM, Kooman JP, Maddux FW. Longitudinal patterns of health-related quality of life and dialysis modality: a national cohort study. BMC Nephrol. 2019;20(1):7.

33. Al-Mansouri A, Al-Ali FS, Hamad Al, Mohamed Ibrahim MI, Kheir N, Ibrahim RA, AlBakri M, Awaisu A.

\section{Assessment of treatment burden and its impact on quality of life in dialysis-dependent and pre- dialysis chronic kidney disease patients in Qatar. Res Social Adm Pharm 2021.}

34. Boini S, Frimat L, Kessler M, Briançon S, Thilly N. Predialysis therapeutic care and health-related quality of life at dialysis onset (The pharmacoepidemiologic AVENIR study). Health Qual Life Outcomes. 2011;9:7.

35. Zelle DM, Klaassen G, van Adrichem E, Bakker SJ, Corpeleijn E, Navis G. Physical inactivity: a risk factor and target for intervention in renal care. Nat Rev Nephrol. 2017;13(3):152-68.

36. Manfredini F, Mallamaci F, D'Arrigo G, Baggetta R, Bolignano D, Torino C, Lamberti N, Bertoli S, Ciurlino D, Rocca-Rey L, et al. Exercise in Patients on Dialysis: A Multicenter, Randomized Clinical Trial. J Am Soc Nephrol. 2017;28(4):1259-68.

37. Sheshadri A, Kittiskulnam P, Johansen KL. Higher Physical Activity Is Associated With Less Fatigue and Insomnia Among Patients on Hemodialysis. Kidney Int Rep. 2019;4(2):285-92.

38. Wilkinson TJ, Shur NF, Smith AC. "Exercise as medicine" in chronic kidney disease. Scand J Med Sci Sports. 2016;26(8):985-8.

39. McAuley E, Blissmer B. Self-efficacy determinants and consequences of physical activity. Exerc Sport Sci Rev. 2000;28(2):85-8.

40. Rajati F, Sadeghi M, Feizi A, Sharifirad G, Hasandokht T, Mostafavi F. Self-efficacy strategies to improve exercise in patients with heart failure: A systematic review. ARYA Atheroscler. 2014;10(6):319-33.

41. Selzler AM, Rodgers WM, Berry TR, Stickland MK. Coping Versus Mastery Modeling Intervention to Enhance Self-efficacy for Exercise in Patients with COPD. Behav Med. 2020;46(1):63-74.

42. Peters M, Potter CM, Kelly L, Fitzpatrick R. Self-efficacy and health-related quality of life: a crosssectional study of primary care patients with multi-morbidity. Health Qual Life Outcomes. 2019;17(1):37. 
43. Selzler AM, Habash R, Robson L, Lenton E, Goldstein R, Brooks D. Self-efficacy and health-related quality of life in chronic obstructive pulmonary disease: A meta-analysis. Patient Educ Couns. 2020;103(4):682-92.

44. Kang SH, Do JY, Jeong HY, Lee SY, Kim JC. The Clinical Significance of Physical Activity in Maintenance Dialysis Patients. Kidney Blood Press Res. 2017;42(3):575-86.

45. Hornik B, Duława J. Frailty, Quality of Life, Anxiety, and Other Factors Affecting Adherence to Physical Activity Recommendations by Hemodialysis Patients. Int J Environ Res Public Health 2019, 16(10).

46. Tsai YC, Chen HM, Hsiao SM, Chen CS, Lin MY, Chiu YW, Hwang SJ, Kuo MC. Association of physical activity with cardiovascular and renal outcomes and quality of life in chronic kidney disease. PLoS One. 2017;12(8):e0183642.

47. Klompstra L, Jaarsma T, Strömberg A. Self-efficacy Mediates the Relationship Between Motivation and Physical Activity in Patients With Heart Failure. J Cardiovasc Nurs. 2018;33(3):211-6.

\section{Figures}

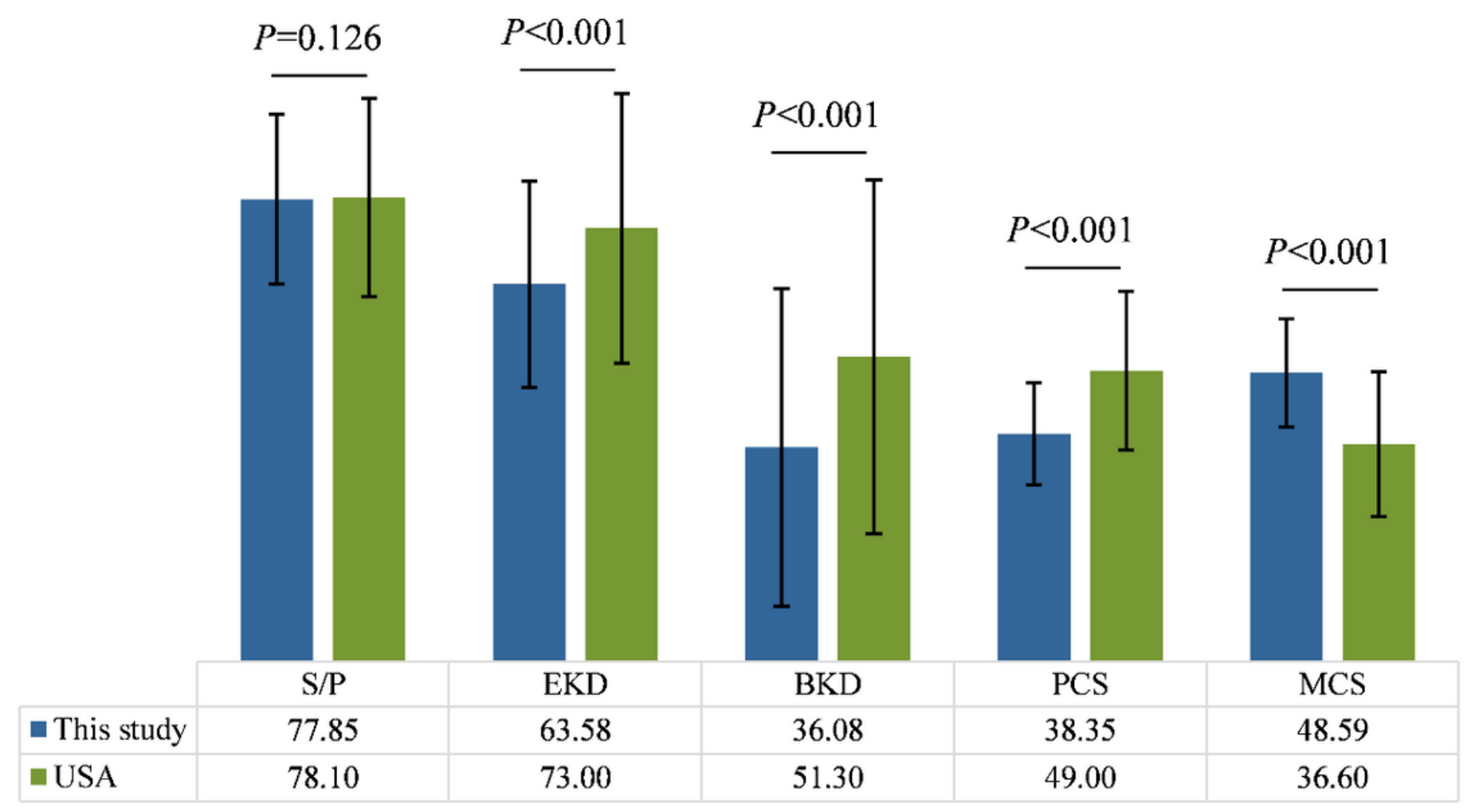

Figure 1

Comparison of HRQOL with the USA dialysis population Figure legend: The USA data was extracted form Cohen DE, Lee A, Sibbel S, Benner D, Brunelli SM, Tentori F: Use of the KDQOL-36 ${ }^{\text {TM }}$ for assessment of 
health-related quality of life among dialysis patients in the United States. BMC Nephrol 2019, 20(1):112. The comparison was based on a one-sample Wilcoxon test.

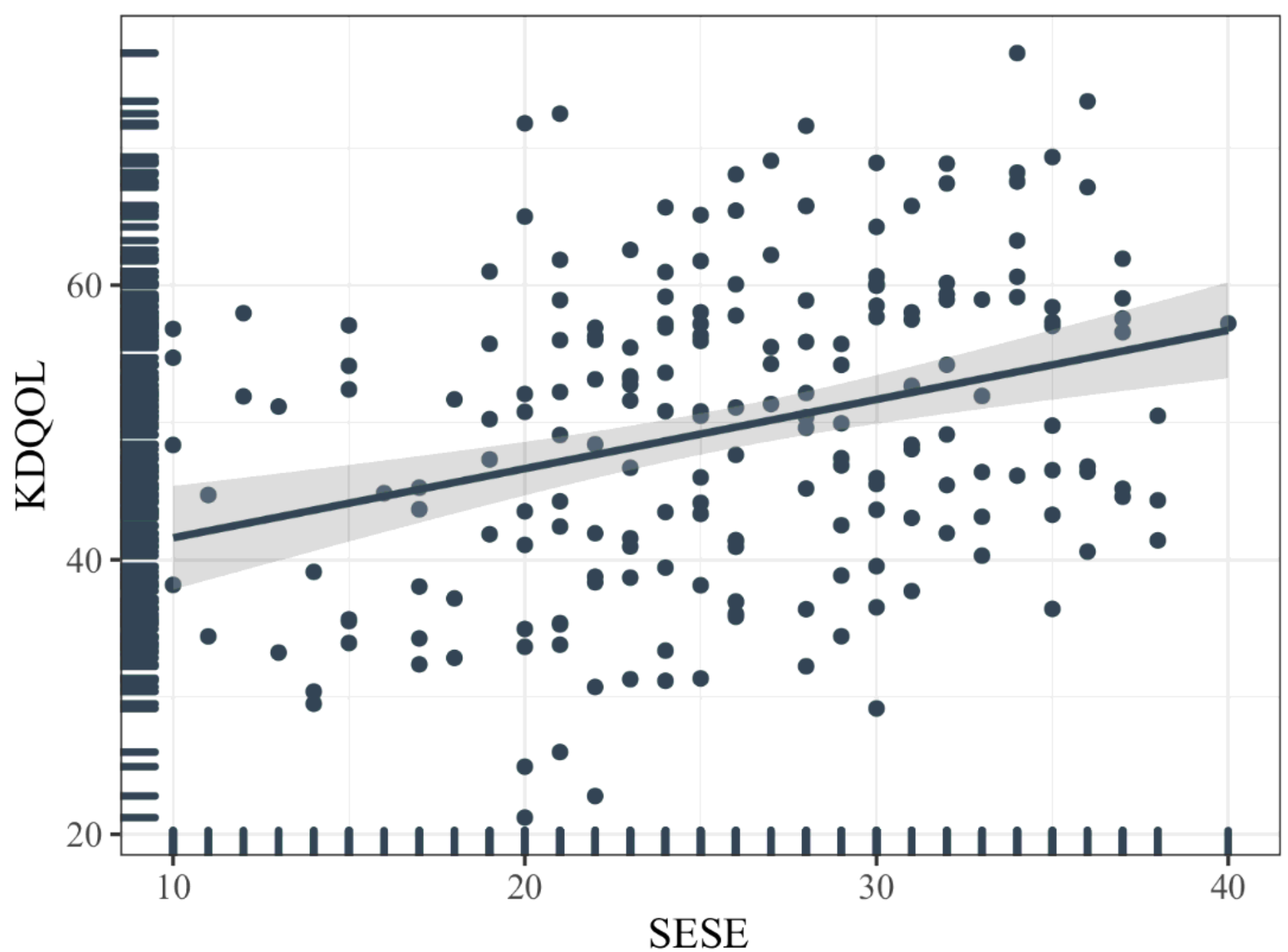

Figure 2

Correlation between exercise self-efficacy and HRQOL Figure legend: The $x$-axis represents exercise selfefficacy and the $y$-axis represents HRQOL, which are positively correlated. 